\title{
Date Data Type
}

National Cancer Institute

\section{Source}

National Cancer Institute. Date Data Type. NCI Thesaurus. Code C48871.

A string unique to a time duration of 24 hours between 2 successive midnights defined by the local time zone. The specific representation of a date will depend on which calendar convention is in force as well as local ordering conventions. 